\title{
Effect of isoniazid preventive therapy on tuberculosis incidence and associated risk factors among HIV infected adults in Tanzania: a retrospective cohort study
}

\author{
Amon Sabasaba ${ }^{1 *}$ D, Henry Mwambi ${ }^{1,2}$, Geoffrey Somi ${ }^{3}$, Angella Ramadhani ${ }^{3}$ and Michael J. Mahande
}

\begin{abstract}
Background: Tuberculosis (TB) continues to be the leading cause of morbidity and mortality among human immunodeficiency virus (HIV) infected individuals in Sub Saharan Africa including Tanzania. Provision of isoniazid preventive therapy (IPT) is one of the public health interventions to reduce the burden of TB among HIV infected persons. However there is limited information about the influence of IPT on TB incidence in Tanzania. This study aimed at ascertaining the effect of IPT on TB incidence and to determine risk factors for TB among HIV positive adults in Dar es Salaam region.
\end{abstract}

Methods: A retrospective cohort study was conducted using secondary data of HIV positive adults receiving care and treatment services in Dar es Salaam region from 2011 to 2014. TB incidence rate among HIV positive adults on IPT was compared to those who were not on IPT during the follow up period. Risk factors for incident TB were estimated using multivariate Cox proportional hazards regression model.

Results: A total of 68,378 HIV positive adults were studied. The median follow up time was 3.4 (IQR = 1.9-3.8) years for patients who ever received IPT and $1.3(\mathrm{IQR}=0.3-1.3)$ years among those who never received IPT. A total of 3124 TB cases occurred during 114,926 total person-years of follow up. The overall TB incidence rate was 2.7/100 person-years $(95 \% \mathrm{Cl} ; 2.6-2.8)$. Patients on IPT had $48 \%$ lower TB incidence rate compared to patients who were not on IPT (IRR $=0.52,95 \% \mathrm{Cl} ; 0.46-0.59)$. Factors associated with higher risk for incident TB included; being male (aHR= $1.8,95 \% \mathrm{Cl} ; 1.6-2.0)$, WHO stage III $(\mathrm{aHR}=2.7,95 \% \mathrm{Cl} ; 2.3-3.3)$ and $\mathrm{IV}(\mathrm{aHR}=2.4,95 \% \mathrm{Cl} ; 1.9-3.1)$,being underweight $(\mathrm{aHR}=1.7,95 \% \mathrm{Cl} ; 1.5-1.9)$ while overweight $(\mathrm{aHR}=0.7,95 \% \mathrm{Cl} ; 0.6-0.8)$, obese (aHR=0.5, 95\% Cl; 0.4-0.7), having

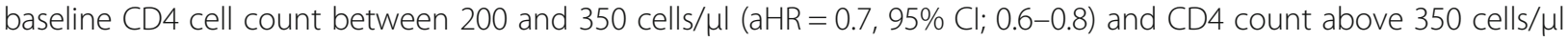
(aHR $=0.5,95 \% \mathrm{Cl} ; 0.4-0.6)$ were associated with lower risk of developing TB.

Conclusion: Isoniazid preventive therapy (IPT) has shown to be effective in reducing TB incidence among HIV infected adults in Dar es Salaam. More efforts are needed to increase the provision and coverage of IPT.

Keywords: TB incidence, Isoniazid preventive therapy, Dar es salaam, Tanzania

\footnotetext{
* Correspondence: amons4u@gmail.com

${ }^{1}$ Department of Epidemiology and Biostatistics, Institute of Public Health,

Kilimanjaro Christian Medical University College, P.O.Box 2240, Moshi,

Tanzania

Full list of author information is available at the end of the article
}

(c) The Author(s). 2019 Open Access This article is distributed under the terms of the Creative Commons Attribution 4.0 International License (http://creativecommons.org/licenses/by/4.0/), which permits unrestricted use, distribution, and reproduction in any medium, provided you give appropriate credit to the original author(s) and the source, provide a link to the Creative Commons license, and indicate if changes were made. The Creative Commons Public Domain Dedication waiver (http://creativecommons.org/publicdomain/zero/1.0/) applies to the data made available in this article, unless otherwise stated. 


\section{Background}

Despite the availability of antiretroviral therapy (ART), Tuberculosis (TB) is the most common presenting illness among people infected with Human Immunodeficiency syndrome Virus (HIV) [1]. People living with HIV are at about thirty times higher risk of developing TB compared to non-HIV infected individuals [2]. HIV co-infection have been associated with unusual presentations of TB such as smear negative and abnormal chest radiographs thus causing a diagnostic challenge, poor treatment outcome and subsequent increased mortality $[3,4]$. In 2017, the World health Organization (WHO) estimated that approximately 10 million people developed TB globally [2]. Of these 9million were adults (5.2 million were male, 3.8 million females) and 1 million were children. During the same period, about 1.3 million HIV negative patients were reported to die of TB, whereas additional 300,000 TB deaths were from HIV infected patients [2].

Isoniazid preventive therapy (IPT) together with other interventions such as intensified case finding and infection control have been widely recommended to reduce the burden of TB in people living with HIV [5]. IPT has been proven to be safe with minimal and less frequently reported side effects such as hepatotoxicity and gastrointestinal symptoms [6]. Studies have shown that IPT can lower TB incidence among PLHIV by up to $70 \%$ if used with or without ART $[7,8]$. However, uptake of IPT has been relatively low in most developing countries including Tanzania [9].

In Tanzania, IPT was widely scaled up in 2011 whereby phase one of the roll out involved ten regions including Dar es salaam [10]. To date it is not well documented to what extent has IPT influenced the TB incidence in Tanzania. Furthermore, little is known on other associated risk factors for TB among HIV positive adults enrolled in care and treatment clinics in Tanzania. This study aims at ascertaining the effect of IPT by comparing TB incidence rates among patients on IPT compared to those not on IPT using routinely collected secondary data. These information are important to policy makers and clinicians to help evaluate the effectiveness of IPT and associated changes in TB incidence in Tanzania particularly Dar es salaam region which is highly endemic for both TB and HIV [11, 12].

\section{Methods}

\section{Study design and setting}

This is a retrospective cohort study which was conducted using de-identified secondary data of HIV positive patients enrolled in fifty (50) Care and treatment clinics (CTCs) in Dar es Salaam region between 2011 and 2014. The study was done in Dar es Salaam region which is the largest city in Tanzania with three districts/ municipalities namely Temeke, Ilala and Kinondoni. Dar es Salaam region is the commercial center with an estimated population of 5 million inhabitants. The region is endemic for both TB and HIV as it contributes about $22 \%$ of all TB notified cases in Tanzania [11] and has an HIV prevalence of $4.7 \%$ which is slightly below the national average of $5.0 \%$ [12].

\section{Study population and period}

The study comprised of all HIV positive adults $(\geq 15$ years) who were enrolled in CTCs of Dar es Salaam region for the first time between January 2011 to December 2014. All patients aged below 15 years, those with missing information on age and those patients who were diagnosed with TB or had documentation of taking Anti TB medications during enrolment were excluded.

\section{Data source and study variables}

We used de-identified secondary data from the electronic database at National Aids Control Program (NACP) which stores routine collected HIV information for patient clinical monitoring and reporting to the government. All patients enrolling in HIV care were registered in the database. Variables were extracted from the database to form a secondary dataset which was used for this analysis. All patients enrolled during the study period were included in the study.

According to the National guideline, it is recommended that for management of HIV all HIV patients attending CTCs should be screened for TB at each clinic visit. This is done using a standard screening algorithm which starts with the use of symptomatic tool and where needed sputum for Acid Fast Bacilli (AFB) and/or a chest radiograph is taken. For this study, the primary outcome was "incident TB" documented in the dataset as a patient newly diagnosed with TB by either Acid-Fast Bacilli sputum smear or chest radiograph or prescribed anti-TB medications during follow-up. The primary exposure was history of using IPT. As per Tanzanian national guideline for management of HIV, eligibility criteria for IPT initiation includes all HIV positive adults without signs and symptoms of active $\mathrm{TB}$ as well as those treated for TB more than two years earlier. IPT is given at a dose of $300 \mathrm{mg}$ daily for six to nine months and should be repeated after two years from the first dose of the IPT cycle. During follow up, some of the patients became eligible for IPT or ART and some were initiated while others were not for reasons we couldn't ascertain from the data.

Other exposure variables included age, sex, weight, height, baseline CD4 count, baseline WHO clinical staging, history of cotrimoxazole use, history of ART use, and other important demographics parameters such as date of enrollment, date of each visit, date of IPT, ART and cotrimoxazole initiation. 


\section{Sampling and sample size estimation}

We used records of all patients who enrolled in care and treatment clinics of Dar es Salaam region between January 2011 and December 2014 which made a total of 74,949 HIV positive patients. Of these, 5.8\% (4328) records were excluded because they were aged less than 15 years and some had missing information on age. Of the remaining records, $2263(3.2 \%)$ were excluded as they were either diagnosed for TB or on Anti TB medications at enrolment as summarized in the flow chart below. The process of obtaining the final sample is summarized in the flow diagram (Fig. 1) below.

\section{Data analysis}

Data analysis was performed using Stata version 13.1 (Stata Corp, College Station, TX). Patient-time at risk for $\mathrm{TB}$ was defined as time from when the client was firstly enrolled in the CTC to the date of first diagnosis of TB, the last date when the patient visited clinic or 31st December 2014 (i.e censoring date) whichever occurred first. A variable for IPT use was treated as time-updated variable whereas a patient in IPT group accrued person time when initiated IPT. Descriptive statistics were summarised using means (SD) and medians (IQR) for continuous variables; frequency and proportion for categorical variables. Kruskal-Wallis test was used to compare the medians for continuous variables. Chi square test was used to determine the association between a set of independent categorical variables and IPT status in bivariate analysis.

The overall ТB incidence rate was computed as the total number of TB cases per total person time recorded. Incidence rate ratio (IRR) was used to compare TB incidence rates between IPT and Non-IPT groups. Multivariable Cox proportional hazards regression model was used to obtain the factors associated with incident TB after accounting for the baseline differences of the two groups. We constructed the model by adding one variable at a time. The decision to keep a variable in the model was done if $P$-value was 0.05 and removal from the model was decided at P-value of more or equal to 0.15 . Finally, Kaplan-Meiyer survival curves were used to estimate cumulative probabilities of being TB free across explanatory variables and then tested using log-rank test. To adjust for the clustering effect of the multi-site level correlation of data, each health facility was considered as a primary sampling unit and proper adjustments were considered during data analysis.

\section{Results}

\section{Characteristics of study participants}

The demographic and clinical characteristics of the study participants are shown in Table 1. A total of 68,378 HIV positive adults were studied. Majority 51,486 (75.3\%) were females. Most of the participants 41,090 (60.1\%) were from Kinondoni district. The median age at enrolment was 35.0 (Inter-quartile range, $\mathrm{IQR}=29.3-41.8$ ) years. Majority 26,648 (39\%) were aged between 26 and 35 years. The mean body mass index (BMI) was 23.3 (standard deviation, $\mathrm{SD}=5.2) \mathrm{kg} / \mathrm{m}^{2}$. Majority $27,704(53.2 \%)$ of the patients had normal BMI. The median CD4+ count was $212(\mathrm{IQR}=118-491) \mathrm{cells} / \mu \mathrm{l}$. A large proportion $(39 \%)$ of the patients had CD4+ count above 350 cells/ $\mu l$. During the study period $6454(9.4 \%)$ patients received Isoniazid preventive therapy (IPT). We compared baseline characteristics between patients who ever received IPT and those who never received IPT during the study (Table 1). We found that, there was a statistically significant difference in all of the characteristics between the two groups except for sex $(P=0.086)$ mean BMI $(P=0.534)$ and median CD4 cell count $(P=0.064)$.

\section{TB incidence rates}

A total of 3124 TB cases were recorded during the study. The median follow-up time between patients on IPT and

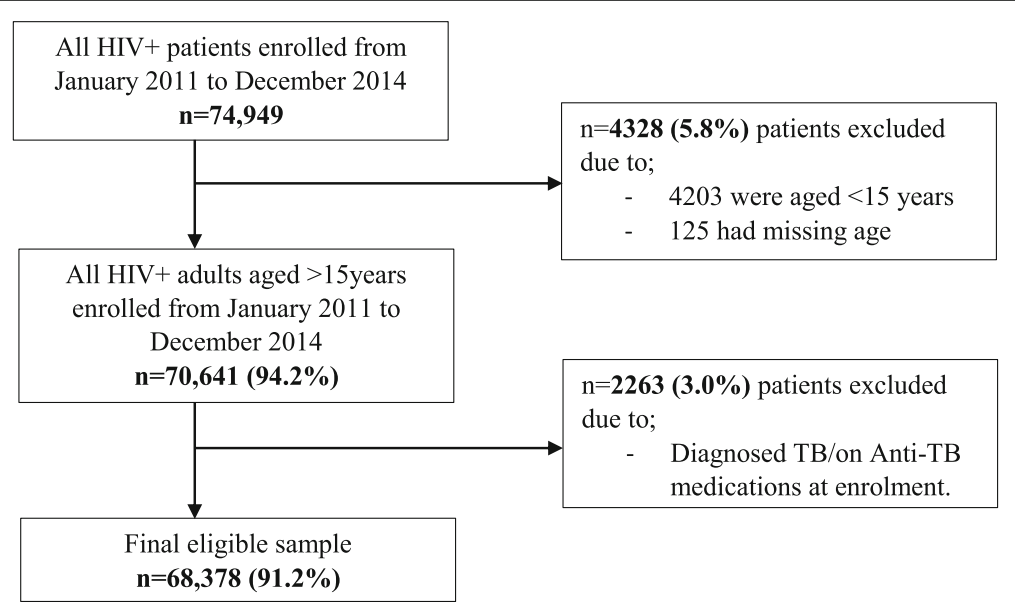

Fig. 1 Flow chart showing the recruitment of the study population 
Table 1 Socio demographic and clinical characteristics of the study participants $(N=68,378)$

\begin{tabular}{|c|c|c|c|c|}
\hline & Total & $\begin{array}{l}\text { Ever received } \\
\text { IPT } \\
(n=6454)\end{array}$ & $\begin{array}{l}\text { Never received IPT } \\
(n=61,924)\end{array}$ & $x^{2}-P$-value ${ }^{*}$ \\
\hline Characteristic & n (\%) & $\mathrm{n}(\%)$ & & \\
\hline Median Age in years (IQR) & $35.0(29.3-41.8)$ & $36.8(31.5-45.5)$ & $34.7(29-41.6)$ & 0.001 \\
\hline Age category (years) & & & & 0.001 \\
\hline $15-25$ & $7500(11.0)$ & $362(5.6)$ & 7138 (11.5) & \\
\hline $26-35$ & $26,648(39.0)$ & $2250(34.9)$ & $24,398(39.4)$ & \\
\hline $36-45$ & $22,208(32.5)$ & $2468(38.2)$ & $19,740(31.9)$ & \\
\hline $45+$ & $12,022(17.6)$ & $1374(21.3)$ & $10,648(17.2)$ & \\
\hline Sex & & & & 0.086 \\
\hline Males & $16,892(24.7)$ & $1651(25.6)$ & $15,241(24.6)$ & \\
\hline Females & $51,486(75.3)$ & $4803(74.4)$ & $46,683(75.4)$ & \\
\hline Marital status & & & & 0.001 \\
\hline Single & $19,249(28.1)$ & $1749(27.1)$ & $17,500(28.3)$ & \\
\hline Married/co-habiting & $33,224(48.6)$ & $3094(47.9)$ & $30,130(48.7)$ & \\
\hline Widowed/divorced & $8823(12.9)$ & $991(15.4)$ & $7832(12.6)$ & \\
\hline BMl categories $\left(\mathrm{Kg} / \mathrm{m}^{2}\right)$ & & & & 0.001 \\
\hline Underweight $(<18.5)$ & $8054(11.8)$ & $815(12.6)$ & $7239(11.7)$ & \\
\hline Normal (18.5-24.5) & $27,704(40.5)$ & $2984(46.2)$ & $24,720(39.9)$ & \\
\hline Overweight (25-29.9) & $10,923(16.0)$ & $1136(17.6)$ & $9787(15.8)$ & \\
\hline Obese $(\geq 30)$ & $5446(8.0)$ & $547(8.5)$ & $4899(7.9)$ & \\
\hline Mean BMI (SD) & $23.3(5.2)$ & $23.2(5.0)$ & $23.2(5.2)$ & 0.534 \\
\hline CD4+ categories (cells/ $/ \mu l)$ & & & & 0.001 \\
\hline$<200$ & $12,891(18.9)$ & $1438(22.3)$ & $11,453(18.5)$ & \\
\hline $200-350$ & $9918(14.5)$ & $1317(20.4)$ & $8601(13.9)$ & \\
\hline$>350$ & $14,585(21.3)$ & $1590(24.6)$ & $12,995(21.0)$ & \\
\hline Median CD4+ cell count (IQR) & $252(118-491)$ & $245(119-390)$ & $253(119-417)$ & 0.064 \\
\hline WHO staging for HIV/AIDS & & & & 0.001 \\
\hline । & $22,530(32.9)$ & $1411(21.9)$ & $20,664(36.1)$ & \\
\hline$\|$ & $13,881(20.3)$ & $1587(24.6)$ & $11,652(20.3)$ & \\
\hline III & $25,894(37.9)$ & $2952(45.7)$ & $19,957(34.9)$ & \\
\hline IV & $4485(6.6)$ & $308(4.8)$ & $3666(6.4)$ & \\
\hline Cotrimoxazole use & & & & 0.001 \\
\hline Yes & $63,041(92.2)$ & $6389(99.0)$ & $56,652(91.5)$ & \\
\hline No & $5337(7.8)$ & $65(1.0)$ & $5272(8.5)$ & \\
\hline ART use & & & & 0.001 \\
\hline Yes & $56,245(82.3)$ & $6214(96.3)$ & $50,031(80.8)$ & \\
\hline No & $12,133(17.7)$ & $240(3.7)$ & $11,893(19.2)$ & \\
\hline Functional status at enrolment & & & & 0.001 \\
\hline Ambulatory & $1449(2.1)$ & $58(0.9)$ & $1391(2.2)$ & \\
\hline Bedridden & $381(0.6)$ & $35(0.5)$ & $346(0.6)$ & \\
\hline Working & $66,070(96.6)$ & $6324(98.0)$ & $59,746(96.5)$ & \\
\hline Health facility type & & & & 0.001 \\
\hline Dispensary & $25,858(37.8)$ & $165(2.6)$ & $25,693(41.5)$ & \\
\hline Health center & $18,961(27.7)$ & $1836(28.4)$ & $17,125(27.7)$ & \\
\hline
\end{tabular}


Table 1 Socio demographic and clinical characteristics of the study participants ( $N=68,378$ ) (Continued)

\begin{tabular}{llll}
\hline & Total & $\begin{array}{l}\text { Ever received } \\
\text { IPT } \\
(n=6454) \\
n(\%)\end{array}$ & $\begin{array}{l}\text { Never received IPT } \\
(n=61,924)\end{array}$ \\
Characteristic & $\mathrm{n}(\%)$ & $4435(68.7)$ & $16,972(27.4)$ \\
\hline $\begin{array}{l}\text { Hospital } \\
\text { Health facility ownership } \\
\text { Government (Public) }\end{array}$ & $21,407(31.3)$ & & \\
Private/FBO & $60,596(88.6)$ & $6338(98.2)$ & $54,258(87.6)$ \\
\hline
\end{tabular}

Some variables had missing records * Chi-squared $P$-value

Non-IPT was $(1.3(\mathrm{IQR}=0.3-1.3)$ and $3.4(\mathrm{IQR}=1.9-$ 3.8) respectively. In total, 6454 patients who received IPT and 61,924 patients who did not received IPT contributed to 114,926 person-years of follow-up. The overall TB incidence rate was $2.7 / 100$ person-years $(95 \% \mathrm{CI}$; 2.6-2.8) (Table 2). The incidence rate of TB was $48 \%$ lower amongst patients who received IPT as compared to those who never received IPT (IRR 0.52, 95\%; 0.460.59) (Table 2).

A comparison for the probability of being $\mathrm{TB}$ free at the end of follow-up period between IPT and Non-IPT patients is shown in Fig. 2. Patients who received IPT had higher probability of being TB free at the end of follow up period compared to those who never received IPT $(\log \operatorname{rank} P=0.001)$.

\section{Cox proportional hazards modelling}

In the bivariable analysis, male sex, WHO stage, ART use, Cotrimoxazole use, BMI and Functional status at baseline were significantly associated with increased hazards of developing TB while IPT use, baseline CD4 count and marital status offered protection against TB acquisition (Table 3). In multivariate analysis, we adjusted for sex, marital status, baseline CD4 count, WHO stage and functional status at baseline. A number of factors remained significant predictors for incident TB. Factors associated with significantly increased risk for TB included male patients (aHR $=1.8,95 \% \mathrm{CI} ; 1.6-2.0)$ compared to females, WHO stage III ( $\mathrm{aHR}=2.7,95 \%$ CI; $2.3-3.3$ and IV $(\mathrm{aHR}=2.4,95 \% \mathrm{CI}$; $1.9-3.1)$ compared to patients with WHO stage I, being underweight (aHR $=1.7,95 \% \mathrm{CI} ; 1.5-1.9)$ compared to normal weights as well as history of using ART (aHR $=1.5,95 \%$ CI; $1.0-2.2)$ and cotrimoxazole $(\mathrm{aHR}=2.2$, 95\% CI; 1.43.5) compared to those never used ART or cotrimoxazole respectively. On the other hand, overweight $(\mathrm{aHR}=$
0.7, 95\% CI; 0.6-0.8), obese patients ( $\mathrm{aHR}=0.5,95 \% \mathrm{CI}$; 0.4-0.7), patients with baseline CD4 count between 200 and 350 cells $/ \mu \mathrm{l}(\mathrm{aHR}=0.7,95 \% \mathrm{CI} ; 0.6-0.8)$ and above 350 cells $/ \mu \mathrm{l}(\mathrm{aHR}=0.5,95 \% \mathrm{CI}$; $0.4-0.6)$ as well as patients ever on IPT (aHR $=0.6,95 \% \mathrm{CI}$; $0.5-0.8)$ were associated with significantly lower risk of developing TB. On assessing the effect of IPT on TB incidence for patients ever on ART and those not on ART, we found that among patients ever on ART, IPT was associated with $40 \%(\mathrm{aHR}=0.6,95 \% \mathrm{CI} ; 0.5-0.7)$ reduced risk of developing TB as summarized in Table 4 below.

\section{Discussion}

The overall TB incidence rate of 2.7 per 100 person years in our study is about three fold lower than previous reported by a study in Dar es salaam region [13] . The IPT uptake in our study was only $9.4 \%$. However, TB incidence rate was $48 \%$ lower among patients on IPT compared with non-IPT patients. Being male, underweight (BMI $<18.5 \mathrm{~kg} / \mathrm{m} 2$ ), higher WHO HIV clinical staging (II-IV), use of cotrimoxazole and ART were significantly associated with increased incident $\mathrm{TB}$ in the studied population.

The overall TB incidence rate found in this study is similar to what has been reported by other studies in Sub Saharan Africa which used routine HIV program data [14-16]. The use of HIV program data makes the findings more reliable as the data is collected in real-time and in most cases it is large enough to offer sufficient power to the study. Furthermore, the observed TB incidence rate might imply that most countries in Sub Saharan Africa are experiencing a relatively stable TB incidence given the wide scale-out of various TB preventing interventions including IPT.

The low level of IPT uptake in our study is similar to what has been documented for other countries in Sub

Table 2 Comparison of TB incidence rates among patients ever on IPT against those never on IPT $(N=62,983)$

\begin{tabular}{lllll}
\hline IPT status & Number of TB cases & Total person-years (TPYrs) & Incidence rate (per 100pyrs) & IRR (95\% Cl) \\
\hline Never on IPT & 2845 & 96,845 & 2.94 & 1.0 \\
Ever on IPT & 279 & 18,081 & 1.54 & $0.52(0.46-0.59)$ \\
Total & 3124 & 114,926 & 2.7 & \\
\hline
\end{tabular}




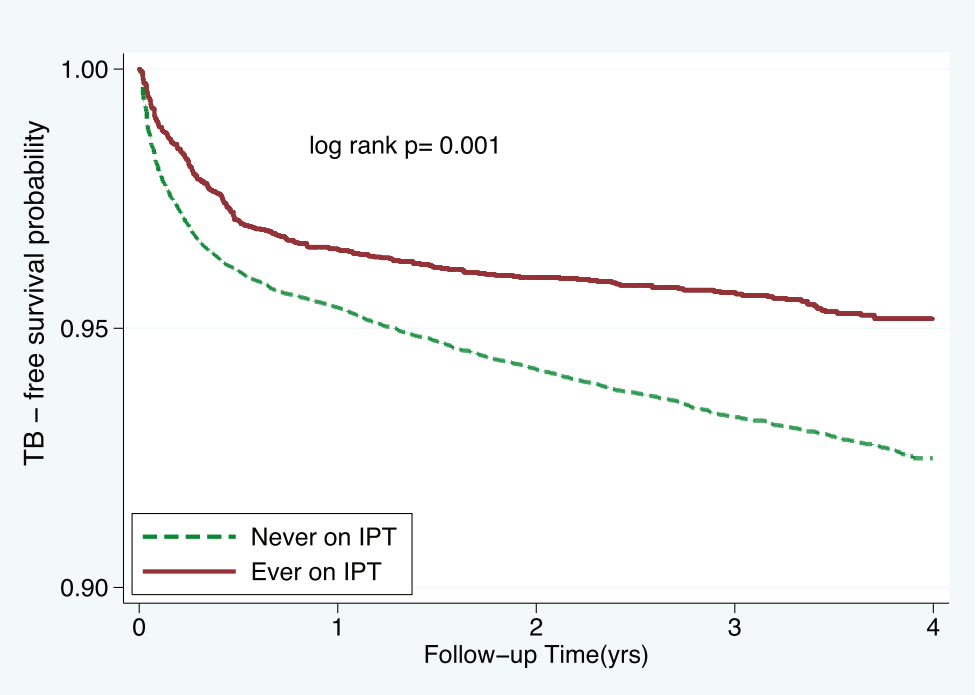

Fig. 2 Kaplan-Meir probability of TB-free survival by IPT status

Saharan Africa [17]. This may be due to regular stock outs and other challenges involved in the supply chain of Isoniazid during the roll out. However, we did not explore the reasons for low IPT uptake in our study.

In the present study, we found that IPT reduces the TB incidence rate among HIV infected adults by almost $50 \%$. Even after adjusting for potential confounders in the multivariable analysis we still found that IPT had a protective effect on TB incidence. The effectiveness of IPT is consistent to findings in Brazil [7] and Ethiopia [16, 18]. We further noted that patients on IPT had a higher TB free survival time compared to non-IPT patients. This finding is in agreement to that reported in South Africa and Ivory Coast $[19,20]$. Despite our study being an observational in nature, but still it reconfirms and adds to the body of knowledge on the effectiveness of IPT in reducing TB burden among HIV infected individuals.

Risk factors for incident TB in our this study are consistent with those reported in previous studies [13, 2124]. We found that being male, BMI, baseline CD4 count, advanced WHO stage, ART use and Cotrimoxazole use were significantly associated with an increased risk of TB incidence.

There are still no clear reasons as to why being male is associated with higher risk of developing TB. One possible explanation from our study could be the fact that most females were enrolled through PMTCT option B+ thus had a protective effect of prior ART exposure and majority of males were enrolled with advanced disease stage. In contrast with previous studies $[4,13]$ the history of using ART alone during follow up did not offer a protective effect against incident TB. However, our study found that the protective effect of IPT against TB was significantly marked among patients ever received ART and this is similar to what have been documented in other studies [19, 24].

\section{Strengths and limitations of the study}

This is one of the few studies in Tanzania which demonstrated the effect of IPT on TB incidence using routine HIV program data. The strength of this study relies on the fact that it involved a large cohort of patients from different facilities (multi-sites). However, our study had some limitations which need to be considered while interpreting the results. Firstly, the eligibility criteria for IPT initiation undertaken in this analysis did not consider past exposure to Isoniazid or repeated course of IPT (i.e. after two years as recommended). This might underestimate the IPT uptake in this study. Secondly, the shorter follow-up time for patients on IPT limited the observed TB cases in this group; possibly we could have observed many cases given a longer follow up time. Thirdly, we did not also assess the differences in loss to follow-p between those who have received IPT and those who have not. This may lead to underestimation or overestimation of the observed effect of the IPT if there is a difference in loss to follow-up between the two groups. Fourthly, we excluded patient with missing records on age status, but there was only small percentage with missing records. However, due to the small percentage of missing records on age, the effect of this exclusion on our finding is unlikely. Fifth, information on routine drug use such as IPT, ART and cotrimoxazole used in this study did not consider details on completion, defaulting or adherence levels during the drug course. Such missing information limits the comparability and generalizability of our findings to the larger population. 
Table 3 Cox proportional hazards analysis of factors associated with incident tuberculosis $(N=62,983)$

\begin{tabular}{|c|c|c|c|c|}
\hline \multirow[t]{2}{*}{ Characteristic } & \multicolumn{2}{|c|}{ Unadjusted } & \multicolumn{2}{|c|}{ Adjusted" } \\
\hline & $\mathrm{HR}$ & $95 \% \mathrm{Cl}$ & $\mathrm{aHR}$ & $95 \% \mathrm{Cl}$ \\
\hline \multicolumn{5}{|l|}{ Age (years) } \\
\hline $15-25$ & 1.0 & & 1.0 & \\
\hline $26-35$ & 1.6 & $1.3-1.9$ & 1.6 & $1.0-2.4$ \\
\hline $36-45$ & 2.1 & $1.8-2.5$ & 1.6 & $1.2-2.2$ \\
\hline $45+$ & 2.2 & $1.7-2.6$ & 1.3 & $0.9-2.0$ \\
\hline \multicolumn{5}{|l|}{ Sex } \\
\hline Females & 1.0 & & 1.0 & \\
\hline Males & 2.4 & $2.2-2.6$ & 1.8 & $1.7-1.9$ \\
\hline \multicolumn{5}{|l|}{ Marital status } \\
\hline Single & 1.0 & & 1.0 & \\
\hline Married/co-habiting & 0.8 & $0.7-0.9$ & 0.9 & $0.8-1.0$ \\
\hline Widowed/divorced & 1.1 & $1.0-1.2$ & 0.9 & $0.8-1.1$ \\
\hline \multicolumn{5}{|l|}{ BMI categories $\left(\mathrm{Kg} / \mathrm{m}^{2}\right)$} \\
\hline Underweight $(<18.5)$ & 2.5 & $2.3-2.7$ & 1.8 & $1.5-2.1$ \\
\hline Normal (18.5-24.5) & 1.0 & & 1.0 & \\
\hline Overweight (25-29.9) & 0.5 & $0.4-0.6$ & 0.7 & $0.6-0.8$ \\
\hline Obese $(\geq 30)$ & 0.4 & $0.3-0.4$ & 0.5 & $0.4-0.7$ \\
\hline \multicolumn{5}{|l|}{ CD4 categories (cells/ul) } \\
\hline$<200$ & 1.0 & & 1.0 & \\
\hline $200-350$ & 0.5 & $0.5-0.6$ & 0.7 & $0.6-0.8$ \\
\hline$>350$ & 0.3 & $0.3-0.4$ & 0.5 & $0.4-0.6$ \\
\hline \multicolumn{5}{|c|}{ WHO clinical staging of HIV } \\
\hline । & 1.0 & & 1.0 & \\
\hline$\|$ & 2.0 & $1.7-2.3$ & 1.4 & $1.2-1.6$ \\
\hline III & 4.4 & $3.9-5.0$ & 2.7 & $2.2-3.2$ \\
\hline IV & 5.3 & $4.5-6.1$ & 2.6 & $1.8-3.9$ \\
\hline \multicolumn{5}{|l|}{ Cotrimoxazole use } \\
\hline No & 1.0 & & 1.0 & \\
\hline Yes & 2.4 & $1.9-3.1$ & 2.2 & $1.3-3.9$ \\
\hline \multicolumn{5}{|l|}{ IPT status } \\
\hline Ever & 0.7 & $0.6-0.7$ & 0.6 & $0.4-0.9$ \\
\hline Never & 1.0 & & & \\
\hline \multicolumn{5}{|l|}{ ART status } \\
\hline Ever & 2.6 & $2.1-3.1$ & 1.5 & $1.0-2.2$ \\
\hline Never & 1.0 & & 1.00 & \\
\hline \multicolumn{5}{|c|}{ Functional status at enrolment } \\
\hline Working & 1.0 & & 1.0 & \\
\hline Bedridden & 1.8 & $1.2-2.8$ & 2.5 & $2.0-3.2$ \\
\hline Ambulatory & 6.1 & $5.3-7.0$ & 1.2 & $0.4-3.2$ \\
\hline
\end{tabular}

adjusted for the effect of age, sex, BMI, CD4 count, WHO stage, IPT use, ART status and Functional status at enrollment
Table 4 The effect of IPT on TB incidence rate among patients by ART status

\begin{tabular}{lllc}
\hline & Characteristic & Hazards ratio $(95 \% \mathrm{Cl})$ & $P$-value \\
\hline Ever on art & Ever on IPT & $0.6(0.5-0.7)$ & 0.001 \\
$(\mathrm{~N}=56,245)$ & Never on IPT & Ref & \\
Never on art & Ever on IPT & $0.5(0.2-1.7)$ & 0.298 \\
$(N=12,133)$ & Never on IPT & Ref & \\
\hline
\end{tabular}

\section{Conclusion and recommendations}

IPT has been shown to decrease the TB incidence rate compared to non-IPT patients regardless of ART use. This suggests the need for IPT to be made available and continuously be given to HIV infected individuals after ruling out active TB. Some factors such as low BMI, advanced WHO stage were associated with an increased risk of TB among HIV infected individuals. This implies that in-depth TB screening and regular follow up should be done among these patients. Future studies should account for factors such as drug adherence and completion status to capture the true effect of IPT on TB incidence as well as involve more geographical regions to represent the whole country.

\section{Abbreviations}

AHR: Adjusted hazards ratio; ART: Antiretroviral therapy; Cl: confidence interval; CTC: Care and treatment clinics; HIV: Human Immunodeficiency virus; HR: Hazards ratio; IPT: Isoniazid preventive therapy; IQR: Inter quartile range; KCMUCO: Kilimanjaro Christian Medical University College;

MOHCDGEC: Ministry of Health, Community Development, Gender Elderly and Children; PMTCT: Prevention of Mother To Child Transmission of HIV/ AIDS; TB: Tuberculosis; WHO: World Health Organization

\section{Acknowledgements}

We acknowledge the contribution of all staffs at NACP specifically the Strategic Information Unit. Their cooperation and support have led to the successful accomplishment of this work.

\section{Funding}

The authors received no funding for this work.

\section{Availability of data and materials}

The data that support the findings of this study are available from the ministry of health (MOHCDGEC) but restrictions apply to the availability of these data, which were used under license for the current study, and so are not publicly available. Data are however available from the authors upon reasonable request and with permission of MOHCDGEC.

\section{Authors' contributions}

Concept development and study design: AS, HM, MJM; Data acquisition: AS, GS, AR; Supervision of the study: MJM, HM, GS, AR; Data analysis and statistical support: AS, MJM, HM; Critically revised the manuscript: AS, HM, MJM, GS, AR; All authors read and approved the final draft of the manuscript for publication.

\section{Ethics approval and consent to participate}

Ethical approval was obtained from the Kilimanjaro Christian Medical University College (KCMUCO). The need for informed consent was deemed unnecessary since we used secondary data which did not have any identifier and it was unlinked from the database. Permission to use CTC data was sought from the MOHCDGEC through the National Aids Control Program (NACP). 


\section{Consent for publication}

The permission to publish the data was obtained from the NACP after being fully informed about the objectives and findings of the study.

\section{Competing interests}

The authors declare that they have no competing interests.

\section{Publisher's Note}

Springer Nature remains neutral with regard to jurisdictional claims in published maps and institutional affiliations.

\section{Author details}

'Department of Epidemiology and Biostatistics, Institute of Public Health, Kilimanjaro Christian Medical University College, P.O.Box 2240, Moshi, Tanzania. ${ }^{2}$ School of Statistics and Actuarial Sciences, University of Kwazul-Natal, Durban, South Africa. ${ }^{3}$ Ministry of Health, Community Development, Gender Elderly and Children (MOHCDGEC) - National Aids Control Program, Dar es salaam, Tanzania.

Received: 14 September 2017 Accepted: 9 January 2019

Published online: 17 January 2019

\section{References}

1. Dean GL, Edwards SG, Ives NJ, Matthews G, Fox EF, Navaratne L, et al. Treatment of tuberculosis in HIV-infected persons in the era of highly active antiretroviral therapy. AIDS. 2002;16(1):75-83 https://doi.org/10.1097/ 00002030-200201040-00010PMID:11741165.

2. World Health Organization. Global tuberculosis report 2015: World Health Organization; 2015.

3. Worodria W, Massinga-Loembe M, Mayanja-Kizza H, Namaganda J, Kambugu A, Manabe YC, Kestens L, Colebunders R. Antiretroviral treatmentassociated tuberculosis in a prospective cohort of HIV-infected patients starting ART. Clin Dev Immunol 2010 Dec;2011.

4. Sharma SK, Mohan A, Kadhiravan T. HIV-TB co-infection: epidemiology, diagnosis \& management Indian J Med Res 2005;121(4):550-567. PMID:15817963.

5. World Health Organization. WHO policy on collaborative TB/HIV activities: guidelines for national programmes and other stakeholders. In: InWHO policy on collaborative TB/HIV activities: guidelines for national programmes and other stakeholders; 2012.

6. Denholm JT, McBryde ES, Eisen DP, Penington JS, Chen C, Street AC Adverse effects of isoniazid preventative therapy for latent tuberculosis infection: a prospective cohort study. Drug Healthc Patient Saf 2014;6:145149. https://doi.org/10.2147/DHPS.S68837 PMID:25364275.

7. Dowdy DW, Golub JE, Saraceni V, Moulton LH, Cavalcante SC, Cohn S, Pacheco AG, Chaisson RE, Durovni B. Impact of isoniazid preventive therapy for HIV-infected adults in Rio de Janeiro, Brazil: an epidemiological model. J acquired immune deficiency syndromes (1999). 2014;66(5):552.

8. Teferi T, Iyaloo J, Kalibbala M, Makai M, Hango JN, Nkongolo OT. Effect of primary isoniazid preventive therapy on tuberculosis incidence rate among HIV-infected adults enrolled in HIV care in northern Namibia 2012: a retrospective cohort study. AIDS 2012. Presented at the - 19th International AIDS Conference, 2012: Abstract WEPE066. 22-27 July 2012. Washington, D.C.

9. World Health Organization. Global tuberculosis report 2014. In: World Health Organization; 2014.

10. Ramadhani A, Josiah RM, Rwebembera A, Msuya EL, Swai R, Urassa P, Kalluvya S, Omari S, Kaganda J, Kibao A. Schimana W. National guidelines for the management of HIV and AIDS.

11. National Tuberculosis and Leprosy Programme (NTLP). Manual for the management of tuberculosis and leprosy. In: 6th ed; 2013.

12. Zanzibar AIDS Commission. Tanzania HIV/AIDS and malaria indicator survey 2011-12.

13. Liu E, Makubi A, Drain P, Spiegelman D, Sando D, Li N, Chalamilla G, Sudfeld $C R$, Hertzmark E, Fawzi WW. Tuberculosis incidence rate and risk factors among HIV-infected adults with access to antiretroviral Therapy. AIDS (London, England). 2015 Jul;29(11):1391-9.

14. Nakiyingi L, Ssengooba W, Nakanjako D, Armstrong D, Holshouser M, Kirenga BJ, et al. Predictors and outcomes of mycobacteremia among HIVinfected smear- negative presumptive tuberculosis patients in Uganda. BMC Infect Dis. 2015 Feb;15:62.
15. Assebe LF, Reda HL, Wubeneh AD, Lerebo WT, Lambert SM. The effect of isoniazid preventive therapy on incidence of tuberculosis among HIVinfected clients under pre-ART care, Jimma, Ethiopia: a retrospective cohort study. BMC Public Health. 2015;15(1):346.

16. Yirdaw KD, Jerene D, Gashu Z, Edginton ME, Kumar AMV, Letamo Y, et al. Beneficial effect of isoniazid preventive therapy and antiretroviral therapy on the incidence of tuberculosis in people living with HIV in Ethiopia. PLoS One. 2014;9(8).

17. Churchyard GJ, Mametja LD, Mvusi L, Ndjek N, Hesseling AC, Reid A, et al. Tuberculosis control in South Africa: successes, challenges and recommendations. S Afr Med J. 2014 Jan 1;104(3):244-8.

18. Semu M, Fenta TG, Medhin G, Assefa D. Effectiveness of isoniazid preventative therapy in reducing incidence of active tuberculosis among people living with HIV/AIDS in public health facilities of Addis Ababa, Ethiopia: a historical cohort study. BMC Infect Dis. 2017 Jan;17(1):5.

19. Golub JE, Pronyk P, Mohapi L, Thsabangu N, Moshabela M, Struthers H, et al. Isoniazid preventive therapy, HAART and tuberculosis risk in HIV-infected adults in South Africa: a prospective cohort. AIDS Lond Engl. 2009 Mar;23(5): 631-6.

20. Temprano ANRS 12136 Study Group. A trial of early antiretrovirals and isoniazid preventive therapy in Africa. N Engl J Med. 2015 Aug;373(9):808-22.

21. Venkatesh PA, Bosch RJ, Mclntosh K, Mugusi F, Msamanga G, Fawzi WW. Predictors of incident tuberculosis among HIV-1-infected women in Tanzania. The International Journal of Tuberculosis and Lung Disease. 2005 Oct;9(10):1105-11.

22. Van Rie A, Westreich D, Sanne I. Tuberculosis in patients receiving antiretroviral treatment: incidence, risk factors, and prevention strategies. J Acquir Immune Defic Syndr. 2011 Apr;56(4):349-55.

23. Chang CA, Meloni ST, Eisen G, Chaplin B, Akande P, Okonkwo P, Rawizza HE, Tchetgen Tchetgen E, Kanki PJ. Tuberculosis incidence and risk factors among human immunodeficiency virus (HIV)-infected adults receiving antiretroviral therapy in a large HIV program in Nigeria. In Open forum infectious diseases 2015 Dec 1 (Vol. 2, no. 4). Oxford University Press. https://doi.org/10.1093/ofid/ofv154

24. Rangaka MX, Wilkinson RJ, Boulle A, Glynn JR, Fielding K, van Cutsem G, et al. Isoniazid plus antiretroviral therapy to prevent tuberculosis: a randomised double-blind, placebo-controlled trial. Lancet. 2014;384(9944): 682-90. https://doi.org/10.1016/S0140-6736(14)60162-8. 24835842.
Ready to submit your research? Choose BMC and benefit from:

- fast, convenient online submission

- thorough peer review by experienced researchers in your field

- rapid publication on acceptance

- support for research data, including large and complex data types

- gold Open Access which fosters wider collaboration and increased citations

- maximum visibility for your research: over $100 \mathrm{M}$ website views per year

At BMC, research is always in progress.

Learn more biomedcentral.com/submissions 